\title{
The sensational discovery of X-rays
}

\author{
W. C. Röntgen discovered X-rays about this time a century ago. Within a few months, Becquerel was making the \\ first observations of radioactivity. But the beginnings of the then new physics were not a tidy business.
}

Würzburg. Later this year, the university in this mediaeval Bavarian city will be celebrating the centenary of the discovery of X-rays by W. C. Röntgen, its most famous son. As with most centenaries the precise date on which the celebrations should take place is a matter for conjecture. Röntgen spent just over a decade in Würzburg before moving to Munich as head of the physical institute there. Before his death, he arranged that his personal papers should be destroyed, so there are no laboratory notebooks through which his successors can search for the first evidence that an electrical discharge in a Crookes tube can sometimes produce what were called actinic rays.

Of course, the landmark really to celebrate would have been the day on which he took the evocative X-ray photograph of the bones of his wife's hand, but it is not known when that may have been. By default and by convention, the day to celebrate is therefore taken to be that at the end of November 1895 when Röntgen read a paper entitled "On a new kind of rays" to the Würzburg scientific society.

Although the Würzburg society published Röntgen's paper promptly, dissemination of news of the discovery began only with the publication of a translation of Röntgen's paper in Nature on 23 January 1896. Because the Nature archive is in an even more parlous condition than the Röntgen archive, only surmise allows a reconstruction of what happened. Probably Sir Arthur Schuster, then at the University of Manchester, had been given a copy of the paper and urged Nature to translate it.

The evidence for that is internal to the published journal. Nature's first reference to Röntgen's work was on 16 January 1896 , when, in a short anonymous note, the then assistant editor, Richard Gregory (editor from 1919 to 1942), wrote:

Professor W. C. Röntgen . . . is reported to have discovered that a number of substances which are opaque to visible rays of light, are transparent to certain rays capable of affecting a photographic plate. It is alleged that he has been able to utilise his discovery to photograph metals enclosed in wooden or woollen coverings, and has succeeded in obtaining pictures showing only the bones of living persons ..... The scientific world will look forward with interest to the publication of Professor Röntgen's work.

Gregory was telling readers that something of a scoop would follow.
The English translation of Röntgen's paper appeared on 23 January 1896, with a brief commentary by Schuster. Considering the content of the paper, Röntgen's use of terms was meticulously modest. $\mathrm{He}$ used the term "X-rays", but "for the sake of brevity" only. Otherwise, the paper is as sober as anybody could ask: most obstacles are transparent to $\mathrm{X}$-rays, at least when they are sufficiently thin; the transparency of solid objects to X-rays is not simply an inverse function of their mass-density; materials such as aluminium are, mass for mass, more transparent than, say, lead.

Röntgen went on to show that X-rays are neither refracted nor reflected as are rays of ordinary light, but that materials opaque to X-rays also backscatter them, exhibiting what he called "turbidity". $\mathrm{He}$ showed that the X-rays were produced by the impact of cathode rays in a discharge tube on the walls of the tube (and that the apparent source could be moved about by means of a magnet).

What could they be, these X-rays? Certainly not ultraviolet light, which was known to be capable of being reflected, refracted and even polarized, in accordance with Maxwell's theory of electromagnetic waves which, among other things, allowed only for the vibrations of the field in which the electric and magnetic fields are mutually orthogonal and also perpendicular to the direction of the ray. So might not X-rays be the 'missing' longitudinal version of Maxwell waves? Röntgen concludes his paper by saying:

I must confess that I have in the course of this research made myself more and more familiar with this thought, and venture to put the opinion forward, while I am quite conscious that the hypothesis advanced still requires a more solid foundation.

In his comment on Röntgen's paper, Schuster acknowledged that this "remarkable discovery will materially affect our views concerning the relation between the ether and matter", but did not like Röntgen's invocation of longitudinal electromagnetic waves. Röntgen, he complained, had not proved that the new rays were not electromagnetic radiation of the kind that Maxwell had foreseen, but of much smaller wavelength than any radiation previously described. Schuster argued that Röntgen's failure to demonstrate interference might be explained by the incoherence of the source, his failure to demonstrate the refraction as a sign that the wavelength of the X-rays is much less than interatomic distances in real solids. In a perceptive sentence, Schuster added:

If Röntgen's rays contain waves of very small length, the vibrations in the molecules which respond to them would seem to be of a very different order of magnitude from those so far known. Possibly we have here the vibration of the electron within the molecule, instead of that of the molecule carrying with it that of the electron.

Within a few years, Nature had published several hundreds of contributions on what it persisted in calling "Röntgen's rays", from Germany, France, Italy and the United States as well as Britain. The central question was the nature of the new phenomenon.

It is possible to appreciate the flavour of the arguments that followed only by recalling that the search for the "luminiferous ether" was still under way, and that J. J. Thomson had not yet proved that "corpuscles of electricity", otherwise electrons, exist with a mass less than the masses of atoms and with negative electric charge. But Thomson's frequent contributions to the debate in the columns of Nature vividly illustrate the evolution of his thinking on the nature of electricity.

In practice, there was evidence within about a year of classical diffraction in an account of the transmission of X-rays through a tapering metal slit laid on a photographic plate; the image is more blurred as the width of the slit tapers away to nothing. But the issue was not finally resolved until 1912, with the demonstration of X-ray diffraction from a crystal by Max von Laue.

In this welter of publication, there is a poignant comment. On 20 February 1896 , there appears a letter from William Ramsey, who had (with Lord Rayleigh) only recently discovered argon, under the title "Science and morals":

A habit has been growing in recent years. ... After the announcement of an interesting discovery, a number of persons at once proceed to make further experiments, and to publish their results. To me, it appears fair and courteous, before publication, to request the permission of the original discoverer.

Ramsey was aggrieved that his own work had also been exploited by others, but he also roundly declared that if the practice were to become widespread, "scientific men will provide their laboratories with a good lock". Ramsey's opinions had little influence on Nature's contributors to the X-ray debate. Certainly, modest Röntgen had no complaint.

John Maddox 